\title{
Review Article \\ Research on Plants for the Understanding of Diseases of Nuclear and Mitochondrial Origin
}

\author{
Claudia P. Spampinato ${ }^{1}$ and Diego F. Gomez-Casati ${ }^{1,2}$ \\ ${ }^{1}$ Centro de Estudios Fotosintéticos y Bioquímicos (CEFOBI-CONICET), Universidad Nacional de Rosario, Suipacha 531, \\ 2000 Rosario, Argentina \\ ${ }^{2}$ Department of Plant Biotechnology, Universidad Nacional de General San Martin (UNSAM), Avenida General Paz 5445,
} 1650 San Martín, Buenos Aires, Argentina

Correspondence should be addressed to Claudia P. Spampinato, spampinato@cefobi-conicet.gov.ar and Diego F. Gomez-Casati, gomezcasati@cefobi-conicet.gov.ar

Received 17 February 2012; Accepted 28 March 2012

Academic Editor: Marina Clemente

Copyright ( 2012 C. P. Spampinato and D. F. Gomez-Casati. This is an open access article distributed under the Creative Commons Attribution License, which permits unrestricted use, distribution, and reproduction in any medium, provided the original work is properly cited.

\begin{abstract}
Different model organisms, such as Escherichia coli, Saccharomyces cerevisiae, Caenorhabditis elegans, Drosophila melanogaster, mouse, cultured human cell lines, among others, were used to study the mechanisms of several human diseases. Since human genes and proteins have been structurally and functionally conserved in plant organisms, the use of plants, especially Arabidopsis thaliana, as a model system to relate molecular defects to clinical disorders has recently increased. Here, we briefly review our current knowledge of human diseases of nuclear and mitochondrial origin and summarize the experimental findings of plant homologs implicated in each process.
\end{abstract}

\section{Introduction}

Sequencing of the human genome has been fundamental to progress in the study of genetic diseases. In recent years, the research on various human disorders and the influence of protein and gene interactions to disease state have increased. Several model systems have been used to investigate different human diseases such as cell lines (i.e., fibroblasts, human, and mammalian cell lines), yeast (i.e., Saccharomyces cerevisiae), as well as other organisms such as Caenorhabditis elegans and Drosophila melanogaster [1]. Besides these organisms, plants, especially Arabidopsis thaliana, have proven to be a powerful additional model system to study eukaryotic mechanisms that might act similarly in the onset of human diseases [2]. In fact, Arabidopsis encodes several orthologs of human proteins [2]. In addition, Arabidopsis present some advantages for the study of human diseases: (i) short life cycle, (ii) fast and simple growth on MS medium, (iii) availability of mutants and homozygous lines for almost all genes, (iv) fast and simple plant transformation techniques, (v) fast and easy cell culture methods, and (vi) few ethical requirements [1].

The following sections review aspects of some human diseases of nuclear and mitochondrial origin and describe experimental advantages and recent studies of plant homologs implicated in each process.

\section{DNA Repair Genetic Disorders}

\subsection{MMR Pathway}

2.1.1. Hereditary Nonpolyposis Colon Cancer. Hereditary nonpolyposis colon cancer (HNPCC) or Lynch syndrome is an autosomal dominant disease characterized by the early occurrence of cancers of colon, endometrium, and other organs. Tumors are recognized by a high occurrence of microsatellite sequence instability (MSI) [3]. Microsatellites are tandem repeat nucleotides comprising $1-6$ bp that occur ubiquitously throughout the genomes. These sequences undergo changes in the number of repeat units due to 
slippage and inefficient proofreading activity of replicative DNA polymerases and to failure of mismatch repair (MMR) system.

The MMR system is best known for its role in the correction of mispaired and unpaired bases that arise during DNA replication and genetic recombination [4-10]. The system involves several nuclear proteins, which function in sequence. First, MutS proteins recognize DNA damage. Subsequently, MutS proteins recruit MutL proteins at the DNA lesion site in the presence of ATP. Then, proteins implicated in multiple DNA metabolic pathways (exonuclease I (Exo I), proliferating cell nuclear antigen (PCNA), replication factor $\mathrm{C}$ (RFC), single-strand binding protein RPA, high-mobility group box 1 (HMGB1), DNA polymerase $\delta$ and DNA ligase) excise the damaged DNA section and resynthesize the correct DNA sequence.

MutS and MutL proteins form heterodimers in eukaryotes. MutS heterodimers are composed of MutS homologs (MSH) subunits, which assemble as MSH2-MSH6 (MutS $\alpha$ ) and MSH2-MSH3 (MutS $\beta$ ). MutS $\alpha$ recognizes base-base mismatches and short insertion/deletion loops (IDLs) [1116], while MutS $\beta$ binds larger IDLs [11, 14, 17-20]. MutL heterodimers are composed of MutL homologs (MLH) and postmeiotic segregation (PMS) subunits, which in humans assemble as MLH1-PMS2 (MutL $\alpha$ ), MLH1-MLH3, and MLH1-PMS1 [7, 21, 22].

Inherited mutations in one of four different MMR genes (MSH2, MSH6, MLH1, and PMS2) are responsible for predisposition to HNPCC development [23]. Germline mutations in $\mathrm{MSH} 2$ or $\mathrm{MLH1}$ lead to complete loss of DNA MMR activity, whereas inactivation of MSH6 or PMS2 shows a less severe form of cancer associated to the functional redundancy of MSH3 and MLH3 genes, respectively (Table 1). Once MMR activity is reduced, genes are prone to base and frameshift mutations and loss of function. The most critical mutated genes are either involved in the regulation of growth, the regulation of apoptosis, or in MMR system itself, which leads to a progressive inactivation of the entire system [23].

Consistent to the essential genome maintenance function performed by MMR system, evolutionary conservation of MMR genes in plants is not surprising. Besides MSH2, MSH3, MSH6, MLH1, MLH3, and PMS1 (ortholog to human PMS2), plants encode a unique mismatchrecognition protein named MSH7 [24-29]. MSH7 forms heterodimers with MSH2 leading to the formation of MutS $\gamma$. MutS $\gamma$ preferentially recognizes some base-base mismatches and plays a specific role in meiotic recombination [25, 3032]. Like human MMR proteins, plant counterparts are critical to efficiently promote genomic stability (Table 1 ). Inactivation of Arabidopsis MSH2 by T-DNA insertion or RNA interference generated microsatellite instability at several dinucleotide repeat alleles [33]. These insertion/deletion mutations accumulated during propagation since the fifth generation of mutant plants showed up to 3 -fold more allele shifts per plant than the first generation [34]. Cumulative mutations over generations produced abnormalities in morphology and development, fertility, germination efficiency, seed/silique development, and seed set [34]. Loss of a functional Arabidopsis MLH1 gene also led to a significant reduction in fertility in both homozygotes and heterozygotes [35].

Some advantages of Arabidopsis as a model system to study DNA repair mechanisms are worth mentioning: (i) short generation time for propagating progeny, (ii) availability of both homozygous and heterozygous seeds for comparison, and (iii) different reporter systems based on histochemical staining, bioluminescence generation, or herbicide resistance for mutagenesis analysis. In this regard, several reporter constructs were developed to examine Arabidopsis thaliana MMR function in vivo (reviewed in [36]). Assays were designed to analyze microsatellite instability or monitor the frequency of somatic recombination by restoring $\beta$-glucuronidase activity or conferring tolerance to the herbicide phosphinothricin. Results confirmed that frameshift mutations were dependent on $\mathrm{MSH} 2$ [37]. In addition, MSH2, MLH1, or PMS1 were suggested to play essential roles in suppressing recombination between diverged sequences and indicated the involvement of MLH1 and to a lesser extent $\mathrm{MSH} 2$ in the stimulation of plant homologous mitotic recombination [35, 38-41].

Research in Arabidopsis MMR also included overexpression of functionally impaired mutated proteins. Transgenic plants harboring a truncated form of human PMS2, first identified in kindreds affected with HNPCC, exhibited a dominant negative effect [42]. A similar strategy was used to analyze the role of the highly conserved ATP binding domain of AtPMS1. Introduction of mutant alleles were shown to inhibit the MMR system in Arabidopsis [43].

A better understanding of MMR genes, and the mechanisms in which they contribute, requires the isolation and characterization of the proteins they encode. We successfully overexpressed AtMSH2 and AtPMS1 en Escherichia coli and raised polyclonal-antibodies against these subunits [44, 45]. In addition, in studies to be reported elsewhere, we found that expression of MutL $\alpha$ or MutS $\gamma$ in Saccharomyces cerevisiae leads to a clear increase in yeast mutator rate, suggesting that the expression of the plant proteins somehow affects yeast MMR mechanism.

Taken together, the above-cited studies indicate that MMR system shows high conservation from humans to plants. Disruption of plant MMR genes, either by inactivation or dominant negative inhibition, confirmed the function of their orthologs in humans. Studies can be further extended to analyze DNA damage induction and repair. Considering that human MMR proteins also recognize modified bases generated in response to endogenous or exogenous DNA damaging agents and that Arabidopsis seedlings are relatively sensitive to chemical mutagens and reasonably transparent to UV light, Arabidopsis MMR research promises to yield insights into the processing of such lesions. Recently, the contribution of Arabidopsis and maize MutS $\alpha$ (MSH2-MSH6) to UV-induced DNA lesion repair was investigated [46]. MSH2 and MSH6 genes were reported to be upregulated by UV-B. Consistent with these results, Atmsh 2 and Atmsh6 mutant plants accumulated more DNA lesions relative to wild-type plants. These data 
TABLE 1: Overview of studies linking DNA repair pathways and disorders in humans and plants.

\begin{tabular}{|c|c|c|c|c|c|}
\hline Genetic deficiency $^{\mathrm{a}}$ & $\begin{array}{c}\text { DNA repair pathway } \\
\text { defect }^{\text {b }}\end{array}$ & Human disease ${ }^{c}$ & Reference & Plant disorder ${ }^{\mathrm{d}}$ & Reference \\
\hline $\begin{array}{l}\text { MSH2 } \\
\text { MSH6 } \\
\text { MLH1 } \\
\text { PMS2(1) }\end{array}$ & MMR & HNPCC & {$[23]$} & MSI Homeologous recombination & {$[33,34,37-41]$} \\
\hline $\begin{array}{l}\text { XPA } \\
\text { XPB } \\
\text { XPC } \\
\text { XPD } \\
\text { XPE } \\
\text { XPF } \\
\text { XPG }\end{array}$ & NER & $\mathrm{XP}$ & {$[48]$} & Hypersensitivity to UV & {$[90,93-95,97,98]$} \\
\hline ATM & DSB & AT & {$[101]$} & $\begin{array}{l}\text { Hypersensitivity to } \gamma \text { radiation, } \\
\mathrm{X} \text {-ray, radiomimetic agents }\end{array}$ & {$[115,117,118]$} \\
\hline
\end{tabular}

provide evidence that plant MutS $\alpha$ is associated with the repair of UV-induced DNA lesions.

\subsection{NER Pathway}

2.2.1. Xeroderma Pigmentosum. Xeroderma pigmentosum (XP), meaning parchment pigmented skin, is a rare, autosomal inherited neurocutaneous disorder. XP patients are extremely sensitive to sun exposure (ultraviolet radiation, UV): 45\% develop skin cancer, comprising mostly basal and squamous cell carcinomas, and to a lesser extent melanomas, angiomas, and sarcomas [47-49]. Besides skin cancers, 20\% of the XP patients can develop progressive neurological disabilities. These patients are unable to repair UV-induced DNA damage because they are deficient in nucleotideexcision repair pathway (NER). Different genetic variants occur, thus patients are classified into eight complementation groups of XP named XP-A through XP-G for the respective mutated gene and XP-V for the variant form (Table 1). XP$\mathrm{C}$ and $\mathrm{XP}-\mathrm{A}$ are the most common complementation groups [50].

The NER pathway removes bulky DNA adducts, including cyclobutane pyrimidine dimers (CPDs) and pyrimidine (6-4) pyrimidinone dimers (6-4 PPs) caused by UV radiation. The repair of DNA damage occurs through different steps: (i) damage recognition, (ii) assembly of a preincision complex, (iii) excision of the damaged strand, and (iv) gapfilling DNA synthesis. Two subpathways that differ in the initial damage recognition step operate in parallel. The global genome NER (GG-NER) removes lesions throughout the genome, while the transcription-coupled NER (TC-NER) functions on actively transcribed strands [51, 52].

The GG-NER subpathway involves recognition of the lesion by a heterotrimeric complex containing XPC, HR23B, and centrin together with damaged DNA-binding protein
1 and 2 (DDB1, DDB2, or XPE) [53]. The initial damage detection process involves cycles of XPC (together with DDB1 and DDB2) binding and dissociation from the DNA in search of structure distortions [54-57]. Once a lesion is encountered, XPC changes its conformation and binds DNA with single-stranded character opposite the lesion $[56,58-$ 62].

The TC-NER involves recognition of the lesion through a stalled RNA-polymerase II, which triggers the recruitment of Cockayne syndrome type A (CSA), Cockayne syndrome type $\mathrm{B}$ (CSB), and XPA binding protein 2 (XAB2) to the damage $[59,63]$.

After DNA recognition, the ten-subunit complex transcription factor IIH (TFIIH, comprising XPD and XPB among others) is recruited and GG-NER and TC-NER converge into the same pathway. The DNA helicases XPB and XPD facilitate the partial unwinding of the DNA duplex leading to the recruitment of XPA, RPA, and XPG proteins and formation of a stable preincision complex around the damage site [64-69]. Then, ERCC1-XPF and XPG make DNA incisions, which result in the excision of a 24-32 nucleotide single-strand fragment containing the damaged site [70]. The gap formed is filled by DNA polymerases $\delta, \varepsilon$, or $\kappa$ and associated factors [71]. NER is completed by nick sealing by DNA ligase I or III $\alpha[72]$.

Plants have developed different strategies to counteract UV-induced DNA damage: the accumulation of UV absorbing flavonoids and related phenolic compounds in the upper epidermal layers of leaves [73-77], and the excision of UV-induced DNA adducts by photoreactivation or NER [2, 78-81]. Photoreactivation is mediated by photolyases. Arabidopsis contains two photolyase genes, the UVR2 gene which encodes a CPD photolyase $[82,83]$, and the UVR3 gene, which encodes a 6-4 PP photolyase [84]. In addition to this direct repair process, NER also contributes to maintain genome integrity in plants [85]. Orthologs of XPB and 
XPD helicases have been isolated. Unlike other eukaryotic organisms, $A$. thaliana genome contains two $X P B$ copies, named $X P B 1$ and $X P B 2$, arranged as tandem repeats in headto-tail fashion [86-89]. Expression of both genes varies with developmental stages and across tissues and is modulated by light [88]. Atxpb1 mutant plants are viable but exhibit growth delay, lower seed viability, and loss of germination synchrony, indicating a partially functional redundancy of both XPB1 and XPB2 in DNA repair and transcription [87].

XPD was also shown to function in plant DNA repair. Liu et al. [90] characterized two Arabidopsis mutant lines. A T-DNA disruption of XPD was found to be homozygous lethal. However, plants harboring a point mutation in the $X P D$ gene, which resulted in a substitution of a highly conserved glycine residue (G521E), are viable. These plants show growth defects, decreased UV resistance, and excision of UV photoproducts [90]. Results thus suggest that XPD gene is essential for plant development and is required for UV resistance.

DDB2 (XPE) is also critical for UV-B tolerance in plants. The transcript was reported to be expressed in rice and Arabidopsis proliferating tissues [91, 92] and anthers of Arabidopsis flowers [92]. These transcripts are rapidly induced after UV irradiation [91, 92]. Consistent with these results, $d d b 2$ mutant plants demonstrated a hypersensitivity to UV radiation $[93,94]$ and a dark repair deficiency of UVinduced DNA damage [94]. Combining the $d d b 2$ mutation with a CPD photolyase mutation (uvr2) further sensitized the plants to UV. These findings suggest the involvement of NER system besides photolyases for the repair of UV-induced DNA damage in plants.

Orthologs of human XPF (AtRAD1/UVH1) and XPG (AtRAD2/UVH3) endonucleases have also been characterized in Arabidopsis. AtRAD1 transcript is expressed in all tissues but strongly accumulates in meristems and flowers $[95,96]$. AtRAD1 defective plants (uvh1) display a higher sensitivity to DNA damaging agents than wild-type [95, 97, 98]. More specifically, $\gamma$ radiation of $u v h 1$ plants generated cell expansion but inhibited cell division [98]. This response was reported to be due to a G2-phase cycle arrest [97].

Finally, AtRAD2 transcript appears to be ubiquitously expressed at moderate levels [99]. Plants deficient in AtRAD2 (uvh3 mutant) are substantially more UV-sensitive than the wild-type parent, exhibiting severe leaf yellowing and tissue damage after UV irradiation [99].

Overall, these findings indicate essential roles of XP genes in suppresing toxic effects of UV and another DNAdamaging compounds (Table 1). There are, however, differences among human and plant NER pathways. Arabidopsis has 2 copies of $X P B$ and seems to lack XPA. In addition, AtXPF confers sensitivity to $\gamma$ radiation while the corresponding human gene does not. Further studies are needed to understand NER pathway in higher plants.

\subsection{Double-Strand Break Repair}

2.3.1. Ataxia Telangiectasia. Ataxia telangiectasia (AT) is a rare human autosomal recessive neurodegenerative disorder that is characterized by ataxic movements due to cortical cerebellar degeneration and ocular and cutaneous telangiectasia (dilation of small blood vessels) $[100,101]$. Other features of the disease include increased risk of cancer, with $\sim 70 \%$ of malignancies being lymphomas and $\mathrm{T}$ cell leukemias [100], immunodeficiency [102], sterility, and extreme cellular and chromosomal sensitivity to ionizing radiation [103].

AT cells are defective in the ataxia telangiectasia-mutated (ATM) gene $[101,103,104]$ (Table 1). ATM is a member of the family of phosphatidylinositol-3-OH-kinase-like kinases (PIKK) of serine/threonine protein kinases [105]. Activation in response to double-strand break (DSB) damage involves autophosphorylation and dimer dissociation [106, 107]. Activated ATM phosphorylates different downstream proteins involved in cell cycle arrest and/or apoptosis [100, 108]. Failure to activate ATM in response to DNA damage might attenuate repair and prevent apoptosis. This would then cause an accumulation of genetic lesions that eventually compromise cellular function and viability leading to neurodegeneration [109]. Recently, ATM has also emerged in the general response to reactive oxygen species [110-113].

Arabidopsis also possesses ATM orthologs [114]. AtATM is expressed ubiquitously at low levels, slightly higher in flower buds than in other tissues [114]. atm knockout mutants are particularly sensitive to DNA DSB induced by $\gamma$ radiation, $\mathrm{X}$-ray treatment, and radiomimetic agents (Table 1) $[115,116]$ and are defective in the transcriptional induction of genes involved in DNA metabolism, repair, chromatin, and chromosome structure in response to $\gamma$ irradiation $[115,117,118]$. While ATM function appears to be conserved in plants and humans, the signal transduction pathways in these organisms are not precisely the same. Plants lack apoptotic counterparts of downstream regulators. Transmission of signal from ATM depends on a plantspecific transcription factor SOG1 (suppressor of gamma response 1) [119, 120]. Recent reports have demonstrated that Arabidopsis root and shoot stem cells undergo cell death as a downstream response to DNA damage mediated by ATM $[116,121]$.

Taken together, the above-cited studies demonstrate that the mechanisms connecting DNA damage to downstream effectors in plants do not mirror those in human cells. In fact, plants are continuously exposed to environmental mutagens; thus plants have evolved different strategies to sustain growth under genotoxic stress.

\section{Mitochondrial Disorders}

3.1. Friedreich's Ataxia. Friedreich's ataxia (FA) is an autosomal recesive disease in humans [122-124]. FA causes progressive cardio- and neurodegeneration as well as skeletal muscle abnormalities, increased risk of diabetes, and sometimes liver and renal failure [123, 125-128].

This disorder is caused by a GAA triplet expansion, and/or a point mutation in the FA gene, resulting in a deficiency in the expression of frataxin $[122,129,130]$. Frataxin is a nuclear-encoded mitochondrial protein highly conserved across the evolution and with homologues found in prokaryotes and eukaryotes (Figure 1). This protein is 


\begin{tabular}{|c|c|}
\hline H. sapiens & 94 TYERLAEETLDSLAEFFEDLADKPYTFEDYDVSFGSGVLTVKLGGDI \\
\hline M. musculus & AEETLDSLAEFF EDLADKPYTLEDYDVSFGDGVLTIKLGGDI \\
\hline B. taurus & TYERLAEETLDSLAEFF EDLADKPYTFEDYDVSFGSGVLTVKLGGL \\
\hline D. melanogaster & TYERVCSDTLDALCDYF EELTENASELQGTDVAYSDGVLTVNLGG \\
\hline C. elegans & EYETAADSTLERLSDYFDQIADSFPVSEQFDVSHAMGVLTVNVSK \\
\hline S. cerevisiae & KYHEEADDYLDHLLDSLEELSEAHPD-CIPDVELSHGVMTLEIP- \\
\hline A. thaliana & 80 EFHKLANFTINHLLEKI EDYGDNVQI-DGFDIDYGNEVLTLKLG- \\
\hline T. aestivum & KFHKLADDTIHDLLEKLEEYGDSQQNM-DGFDID \\
\hline O. sativa & EYHKLADETIHDLLEKLEEYGDSLQM-DGFD \\
\hline Z. mays & EFHKLADETIHDLLEKLEEYGDSIQM-DC \\
\hline Consensus & $::$ \\
\hline H. sapiens & G----KNWVYSHDGVSLHELLAAELTKALKT-KLDLSSLAYSGKDA 21 \\
\hline M. musculus & --KNWVYSHDGVSLHELLARELTKALNT-KLDLSSLAYSGKGT 207 \\
\hline B. taurus & G----RNWVYSHDGVSLHELLATELTQALKT-KLDLSALAYSGKDT 211 \\
\hline D. melanogaster & GTVAAGRWIYKHSGQSLHELLQQEIPGILKSQSVDFLRLPYCS--- 19 \\
\hline C. elegans & - --EEGKWTYAHDGEQLDSLLNREFRKILADDRIDFSRHV----- 136 \\
\hline S. cerevisiae & NG----EWVSLRNGTKLTDILTEEVEKAISK-SQ----- \\
\hline A. thaliana & RDA--NAWIYRRTEAKLHKLLEEELENLCGE-PIQLS--------- 187 \\
\hline T. aestivum & AAT--DSWIYRRTGVNLMRLLEKEIGELCGT-PVDLS-------- 197 \\
\hline O. sativa & APT--NCWIYRRTGANLGELLEKEIGELCGT-PVETS---- - \\
\hline Z. mays & GTA--NGWIYKRTGVNLVRLLEKEIGELCGT-PVEL-- - \\
\hline Conséns & \\
\hline
\end{tabular}

FIGURE 1: Sequence alignment of frataxin homologues from different organisms. The amino acid sequence of Homo sapiens (accession no. Q16595), Mus musculus (accession no. O35943), Bos taurus (accession number NP_001074196.1), Drosophila melanogaster (accession no. Q9w385), Caenorhabditis elegans (accession no. Q9TY03), Saccharomyces cerevisiae (accession no. Q07540), Arabidopsis thaliana (accession no. NP_192233.2), Triticum aestivum (accession no. CN010373), Oryza sativa, (accession no. BE040598), and Zea mays (accession no. CA830057) is shown. Alignment was performed by using the CLUSTALW2 method (Protein Weight Matrix Blosum, clustering NJ) (http://www.ebi.ac.uk/Tools/msa/clustalw2/). Identical residues $\left(^{*}\right)$ are marked in black, and conserved substitutions (:) are shaded in gray.

predominantly expressed in tissues with a high energetic demand such as neurons and cardiac muscle $[131,132]$. In addition, frataxin is highly expressed in flowers, a high energy demand tissue in plants [133]. The function of frataxin has not been established yet, but its deficiency was associated with oxidative stress, iron accumulation, decrease activities of several Fe-S containing proteins and a deficiency in oxidative phosphorylation [129, 134-140]. In addition, it was recently described that frataxin would participate in heme metabolism [141-143].

The high conservation of the structure of frataxin allowed the development of models using different organisms such as Saccharomyces cerevisiae, mouse, Caenorhabditis elegans, Drosophila melanogaster, Candida albicans, Escherichia coli, and Salmonella enterica [126, 129, 144148]. In addition, our group has developed two different Arabidopsis lines with reduced expression of frataxin; (i) atfh-1, a homozygous mutant line carrying the T-DNA in the $5^{\prime} \mathrm{UTR}$ region of the AtFH gene, which shows a decrease of about $50 \%$ in AtFH expression [140] and (ii) as-AtFH, an antisense line showing a decrease of about $70 \%$ in frataxin expression [142].

One of the proposed roles of frataxin is its involvement in the maturation of cellular Fe-S proteins. It has been described that the synthesis of Fe-S clusters requires a complex machinery and the participation of several genes [149, 150]. Most of these genes are conserved in bacteria, mammals, and yeasts. In addition, The presence of homologue gene sequences in photosynthetic organisms was recently identified, especially in mitochondria and plastids of Arabidopsis.

Several studies reported the role of yeast frataxin (Yfh1) in the assembly of Fe-S clusters, and the deficiency of frataxin results in decreased activity of $\mathrm{Fe}-\mathrm{S}$ proteins such as aconitase and succinate dehydrogenase $[135,136]$. Similar results were found in other models of frataxin deficiency such as knock out mice and cultured human cells [126]. Moreover, we recently found that the frataxin-deficient Arabidopsis lines atfh- 1 and $a s-A t F H$ also have less than $5 \%$ of total aconitase activity and also a decrease of about $40 \%$ in succinate dehydrogenase (SDH) activity. In addition, these plants show also increased ROS and Fe levels and upregulation of transcripts involved in ROS stress responses [140]. We have also reported that AtFH can participate in heme formation in plants. We found that as-AtFH line shows a decrease level of total heme and also shows downregulation of genes involved in heme metabolism such as HEMA1 and 2, GSA1 and 2, HEMB1 and 2, and AtFC-1 and 2. Furthermore, the deficiency of catalase activity was rescued with the addition of hemin [142]. These results are in agreement with those reported in neuronal cells about the hemin rescue of adrenodoxin, heme A levels, and cytochrome oxidase activity [151]. Taking together, these results allow us to propose Arabidopsis AtFH-deficient lines as interesting models to investigate the biogenesis of $\mathrm{Fe}-\mathrm{S}$ clusters, Fe-S- and hemecontaining proteins, as well as for better understanding the FA human disease.

3.2. Mitochondrial Respiratory Chain Diseases. CI Subunit Mutations. The mitochondrial respiratory chain is composed by about 90 proteins encoded by the nuclear genome and 13 proteins encoded by the mitochondrial DNA. These proteins are organized into five macromolecular complexes (CI to $\mathrm{V}$ ) and play a central role in energy production, generating most of the cellular ATP $[152,153]$.

Most of the about 1500 mitochondrial proteins are nuclear encoded and participates in several pathways such as oxidative phosphorylation, Krebs cycle, fatty acid oxidation, heme and $\mathrm{Fe}-\mathrm{S}$ groups synthesis, $\mathrm{Fe}$ and $\mathrm{Ca}$ homeostasis, 


$\begin{array}{lrll} & & * \\ \text { H. sapiens } & 107 & \text { WENPLMGWASTADPLSN } & 123 \\ \text { M. musculus } & 116 & \text { WENPLMGWASTADPLSN } & 132 \\ \text { B. taurus } & 107 & \text { WENPLMGWASTADPLSN } & 123 \\ \text { D. melanogaster } & 114 & \text { WENPLMGWASSGDPLSN } & 130 \\ \text { A. thaliana } & 84 & \text { WENPLMGWTSTGDPYAN } & 100 \\ \text { P. trichocarpa } & 88 & \text { WENPLMGWTSTGDPYAH } & 104 \\ \text { H. vulgare } & 86 & \text { WENPLMGWTSTGDPYAN } & 102 \\ \text { Z. mays } & 86 & \text { WENPLMGWTSTGDPYAN } & 102 \\ \text { O. sativa } & 88 & \text { WENPLMGWTSTGDPYAN } & 104 \\ \text { G. max } & 75 & \text { WENPLMGWTSTGDPYSH } & 89\end{array}$

FIgURE 2: Sequence alignment of NDUFS4 homologues from different organisms showing the high conservation in the flanking region of D119. The amino acid sequence of Homo sapiens (accession no. NP_002486.1), Mus musculus (accession no. NP_035017.2), Bos taurus (accession no. DAA17925.1), Drosophila melanogaster (accession no. NP_573385), Arabidopsis thaliana (accession no. Q9FJW4), Populus trichocarpa (accession no. XP_002310893), Hordeum vulgare (accession no. BAK01929), Zea mays (accession no. NP_001132398), Oryza sativa (accession no. NP_001060126) and Glycine max (accession no. NP_001235335) are shown. Alignment was performed by using the CLUSTALW2 method (Protein Weight Matrix Blosum, clustering NJ) (http://www.ebi.ac.uk/Tools/msa/clustalw2/). The conserved Asp residue is shown in grey.

aging and cell death, among others [152]. Defects in any of the different mitochondrial pathways can cause mitochondrial diseases. In most of these diseases, the muscle and cerebral function is affected, and because of this, disorders are known as mitochondrial encephalomyopaties [154].

In addition, it has been described that many mutations on the mitochondrial genome can cause a wide variety of clinical syndromes such as LHON (Leber's hereditary neuropathy), LS (Leigh's syndrome), MELAS (mitochondrial encephalomyopathy), sporadic anemia, encephalomyopathy, among others [154].

Due to the evolutionary conservation of several human proteins that are part of the respiratory complexes, it was possible to develop different models such as yeast mutants $[155,156]$ and C. elegans mitochondrial mutants for CI, CII, and CIII [157] to study the pathogenesis of mitochondrial dysfunction in humans. In addition, the presence of homologous proteins in Arabidopsis plants allows us to propose this as a model plant for the study of several mitochondrial diseases related to the mitochondrial respiratory chain dysfunction.

Dysfunction of $\mathrm{CI}$ of the mitochondrial respiratory chain is the most common enzyme defect of mitochondrial disorders, and it is involved in more than $30 \%$ of the hereditary mitochondrial encephalopaties, including Leigh's syndrome. $[158,159]$. CI (NADH: ubiquinone oxidoreductase) is the largest complex of the OXPHOS system. Human CI contains at least 45 protein subunits, 7 encoded by the mitochondrial genome, and 28 by the nuclear DNA [160]. This complex is located on the mitochondrial inner membrane and catalyzes the oxidation of NADH by ubiquinone.

One of the most studied OXPHOS deficiencies is the mutation in the NDUFS 4 gene, a small $18 \mathrm{kD}$ protein of CI highly conserved in different organisms. Mutations in NDUFS4 result in a loss of the last 10-15 amino acids of its final fifth exon and lead to mitochondrial diseases such as Leber's hereditary optic neuropathy (LHON), Leigh's syndrome (LS), and mitochondrial encephalomyopathy, lactic acidosis, and stroke (MELAS). The mutation affects OXPHOS and metabolism by limiting respiratory substrates such as NADH due to the deficiency in CI function [161].
The first mutation found in NDUFS4 was a 5-bp duplication in the ORF of the gene that impairs the phosphorylation of the protein leading to an inactivation of the complex $[162,163]$. Other mutations in patients with Leigh syndrome were found in NDUFS4 such as a homozygous G-A transition at nucleotide +44 of the coding sequence [164]. The G44A mutation results in the change of a TGG codon, which encodes for a tryptophan residue, to a TAA stop codon, which causes the premature termination of the protein, thus obtaining a truncated form of NDUFS4. A third mutation in NDUSF4 was reported, a single-base deletion at position 289/290 [165]. Recently, two novel mutations in NDUFS4 causing Leigh syndrome has been reported [166]. One of these mutations, $\mathrm{D} 119 \mathrm{H}$, is in a conserved region of the protein. Interestingly, the D119 is highly conserved within human, mammals, nematodes, and plant species (Figure 2). All the mentioned mutations were found to be associated with a defect of the assembly of a functional complex in the inner mitochondrial membrane. These data suggest that NDUFS4 has an essential role in the structure and function of CI.

Recently, Meyer et al. [167] reported the characterization of an ndufs4 mutant of A. thaliana. As mentioned above, AtNDUFS4 is highly conserved, showing a $41 \%$ identity respect to the human homolog. NDUFS4-deficient plants show low phosphorylation efficiency, sucrose-sensitive germination, delayed growth, a modified respiration pathway, and altered stress responses. The lack of CI has no major influence on the mitochondrial proteome or transcriptome but leads to a lowering of growth-related nuclear transcripts and clearly influences central metabolism [167]. In addition, the deletion of NDUFS4 prevents the assembly of CI and alters the adenylate control of cellular metabolism without pleiotropic effects on other respiratory components [167]. Taken togheter, these observations show the essential role of the NDUFS4 gene in the structure and function of CI. Moreover, due to evolutionary conservation of this protein, it is possible to use different models, including Arabidopsis, in order to better understand the mechanism of assembly of this respiratory complex, whose dysfunction is responsible for many mitochondrial human diseases. 


\section{Concluding Remarks}

Plants have preserved most of the pathways essential for life and then represent complementary resources within human disease research. As described in this paper, observations demonstrate that plants encode orthologs of human proteins, which function in mechanisms reminiscent of those in other eukaryotes. Thus, plant research opens new areas regarding drug development and disease therapy, which are crucial to human health.

\section{Acknowledgments}

This paper was supported by Grants from Agencia Nacional de Promoción Científica y Tecnológica to Claudia Spampinato (PICT 0458) and Diego Gomez-Casati (PICT 00614 and 0729) and Consejo Nacional de Investigaciones Científicas y Técnicas (CONICET) to Claudia Spampinato (PIP 0018). Claudia Spampinato and Diego Gomez-Casati are research members from CONICET.

\section{References}

[1] X. M. Xu and S. G. Moller, "The value of Arabidopsis research in understanding human disease states," Current Opinion in Biotechnology, vol. 22, pp. 300-307, 2011.

[2] J. B. Hays, "Arabidopsis thaliana, a versatile model system for study of eukaryotic genome-maintenance functions," DNA Repair, vol. 1, no. 8, pp. 579-600, 2002.

[3] H. T. Lynch and A. De la Chapelle, "Hereditary colorectal cancer," New England Journal of Medicine, vol. 348, no. 10, pp. 919-932, 2003.

[4] M. E. Arana and T. A. Kunkel, "Mutator phenotypes due to DNA replication infidelity," Seminars in Cancer Biology, vol. 20, no. 5, pp. 304-311, 2010.

[5] A. Bellacosa, "Functional interactions and signaling properties of mammalian DNA mismatch repair proteins," Cell Death and Differentiation, vol. 8, no. 11, pp. 1076-1092, 2001.

[6] R. R. Lyer, A. Pluciennik, V. Burdett, and P. L. Modrich, "DNA mismatch repair: functions and mechanisms," Chemical Reviews, vol. 106, no. 2, pp. 302-323, 2006.

[7] T. A. Kunkel and D. A. Erie, "DNA mismatch repair," Annual Review of Biochemistry, vol. 74, pp. 681-710, 2005.

[8] P. Modrich and R. Lahue, "Mismatch repair in replication fidelity, genetic recombination, and cancer biology," Annual Review of Biochemistry, vol. 65, pp. 101-133, 1996.

[9] M. J. Schofield and P. Hsieh, "Dna mismatch repair: molecular mechanisms and biological function," Annual Review of Microbiology, vol. 57, pp. 579-608, 2003.

[10] P. Modrich, "Mechanisms in eukaryotic mismatch repair," Journal of Biological Chemistry, vol. 281, no. 41, pp. 3030530309, 2006.

[11] S. Acharya, T. Wilson, S. Gradia et al., "hMSH2 forms specific mispair-binding complexes with hMSH3 and hMSH6," Proceedings of the National Academy of Sciences of the United States of America, vol. 93, no. 24, pp. 13629-13634, 1996.

[12] E. Alani, "The Saccharomyces cerevisiae Msh2 and Msh6 proteins form a complex that specifically binds to duplex oligonucleotides containing mismatched DNA base pairs," Molecular and Cellular Biology, vol. 16, no. 10, pp. 5604-5615, 1996.
[13] J. T. Drummond, G. M. Li, M. J. Longley, and P. Modrich, "Isolation of an hMSH2-p160 heterodimer that restores DNA mismatch repair to tumor cells," Science, vol. 268, no. 5219, pp. 1909-1912, 1995.

[14] J. Genschel, S. J. Littman, J. T. Drummond, and P. Modrich, "Isolation of MutS $\beta$ from human cells and comparison of the mismatch repair specificities of MutS $\beta$ and MutS $\alpha$," Journal of Biological Chemistry, vol. 273, no. 31, pp. 19895-19901, 1998.

[15] S. Gradia, S. Acharya, and R. Fishel, "The human mismatch recognition complex hMSH2-hMSH6 functions as a novel molecular switch," Cell, vol. 91, no. 7, pp. 995-1005, 1997.

[16] F. Palombo et al., "Cisplatin and adriamycin resistance are associated with MutLa and mismatch repair deficiency in an ovarian tumor cell line," Science, vol. 268, pp. 1912-1914, 1995.

[17] R. E. Johnson, G. K. Kovvali, L. Prakash, and S. Prakash, "Requirement of the yeast MSH3 and MSH6 genes for MSH2-dependent genomic stability," Journal of Biological Chemistry, vol. 271, no. 13, pp. 7285-7288, 1996.

[18] F. Palombo, I. Iaccarino, E. Nakajima, M. Ikejima, T. Shimada, and J. Jiricny, "hMutS $\beta$, a heterodimer of hMSH2 and hMSH3, binds to insertion/deletion loops in DNA," Current Biology, vol. 6, no. 9, pp. 1181-1184, 1996.

[19] J. M. Harrington and R. D. Kolodner, "Saccharomyces cerevisiae Msh2-Msh3 acts in repair of base-base mispairs," Molecular and Cellular Biology, vol. 27, no. 18, pp. 6546-6554, 2007.

[20] G. T. Marsischky, N. Filosi, M. F. Kane, and R. Kolodner, "Redundancy of Saccharomyces cerevisiae MSH3 and MSH6 in MSH2-dependent mismatch repair," Genes and Development, vol. 10, no. 4, pp. 407-420, 1996.

[21] B. D. Harfe and S. Jinks-Robertson, "DNA mismatch repair and genetic instability," Annual Review of Genetics, vol. 34, pp. 359-399, 2000.

[22] S. M. Lipkin, V. Wang, R. Jacoby et al., "MLH3: a DNA mismatch repair gene associated with mammalian microsatellite instability," Nature Genetics, vol. 24, no. 1, pp. 27-35, 2000.

[23] C. R. Boland, M. Koi, D. K. Chang, and J. M. Carethers, "The biochemical basis of microsatellite instability and abnormal immunohistochemistry and clinical behavior in Lynch Syndrome: from bench to bedside," Familial Cancer, vol. 7, no. 1, pp. 41-52, 2008.

[24] A. H. Alou, M. Jean, O. Domingue, and F. J. Belzile, "Structure and expression of AtPMS1, the Arabidopsis ortholog of the yeast DNA repair gene PMS1," Plant Science, vol. 167, no. 3, pp. 447-456, 2004.

[25] K. M. Culligan and J. B. Hays, "Arabidopsis MutS homologs-AtMSH2, AtMSH3, AtMSH6, and a novel AtMSH7form three distinct protein heterodimers with different specificities for mismatched DNA," Plant Cell, vol. 12, no. 6, pp. 991-1002, 2000.

[26] M. Jean, J. Pelletier, M. Hilpert, F. Belzile, and R. Kunze, "Isolation and characterization of AtMLH1, a MutL homologue from Arabidopsis thaliana," Molecular and General Genetics, vol. 262, no. 4-5, pp. 633-642, 1999.

[27] J. Adé, F. Belzile, H. Philippe, and M. P. Doutriaux, "Four mismatch repair paralogues coexist in Arabidopsis thaliana: AtMSH2, AtMSH3, AtMSH6-1 and AtMSH6-2," Molecular and General Genetics, vol. 262, no. 2, pp. 239-249, 1999.

[28] N. Jackson, E. Sanchez-Moran, E. Buckling, S. J. Armstrong, G. H. Jones, and F. C. H. Franklin, "Reduced meiotic 
crossovers and delayed prophase I progression in AtMLH3deficient Arabidopsis," EMBO Journal, vol. 25, no. 6, pp. 1315-1323, 2006.

[29] S. M. Tam, S. Samipak, A. Britt, and R. T. Chetelat, "Characterization and comparative sequence analysis of the DNA mismatch repair MSH2 and MSH7 genes from tomato," Genetica, vol. 137, no. 3, pp. 341-354, 2009.

[30] S. Y. Wu, K. Culligan, M. Lamers, and J. Hays, "Dissimilar mispair-recognition spectra of Arabidopsis DNA-mismatchrepair proteins $\mathrm{MSH} 2 \cdot \mathrm{MSH} 6(\mathrm{MutS} \alpha$ ) and $\mathrm{MSH} 2 \cdot \mathrm{MSH} 7$ (MutSy)," Nucleic Acids Research, vol. 31, no. 20, pp. 60276034, 2003.

[31] C. Dong, R. Whitford, and P. Langridge, "A DNA mismatch repair gene links to the Ph2 locus in wheat," Genome, vol. 45, no. 1, pp. 116-124, 2002.

[32] A. H. Lloyd, A. S. Milligan, P. Langridge, and J. A. Able, "TaMSH7: a cereal mismatch repair gene that affects fertility in transgenic barley (Hordeum vulgare L.)," BMC Plant Biology, vol. 7, article 67, 2007.

[33] J. M. Leonard, S. R. Bollmann, and J. B. Hays, "Reduction of stability of Arabidopsis genomic and transgenic DNArepeat sequences (microsatellites) by inactivation of AtMSH2 mismatch-repair function," Plant Physiology, vol. 133, no. 1, pp. 328-338, 2003.

[34] P. D. Hoffman, J. M. Leonard, G. E. Lindberg, S. R. Bollmann, and J. B. Hays, "Rapid accumulation of mutations during seed-to-seed propagation of mismatch-repair-defective Arabidopsis," Genes and Development, vol. 18, no. 21, pp. 2676 2685, 2004.

[35] É. Dion, L. Li, M. Jean, and F. Belzile, "An Arabidopsis MLH1 mutant exhibits reproductive defects and reveals a dual role for this gene in mitotic recombination," Plant Journal, vol. 51, no. 3, pp. 431-440, 2007.

[36] C. P. Spampinato, R. L. Gomez, C. Galles, and L. D. Lario, "From bacteria to plants: a compendium of mismatch repair assays," Mutation Research, vol. 682, no. 2-3, pp. 110-128, 2009.

[37] A. Depeiges, S. Farget, F. Degroote, and G. Picard, "A new transgene assay to study microsatellite instability in wildtype and mismatch-repair defective plant progenies," Plant Science, vol. 168, no. 4, pp. 939-947, 2005.

[38] L. Li, E. Dion, G. Richard, O. Domingue, M. Jean, and F. J. Belzile, "The Arabidopsis DNA mismatch repair gene PMS1 restricts somatic recombination between homeologous sequences," Plant Molecular Biology, vol. 69, no. 6, pp. 675-684, 2009.

[39] L. Li, M. Jean, and F. Belzile, "The impact of sequence divergence and DNA mismatch repair on homeologous recombination in Arabidopsis," Plant Journal, vol. 45, no. 6, pp. 908 916, 2006.

[40] E. Emmanuel, E. Yehuda, C. Melamed-Bessudo, N. AviviRagolsky, and A. A. Levy, "The role of AtMSH2 in homologous recombination in Arabidopsis thaliana," EMBO Reports, vol. 7, no. 1, pp. 100-105, 2006.

[41] J. Lafleuriel, F. Degroote, A. Depeiges, and G. Picard, "Impact of the loss of AtMSH2 on double-strand break-induced recombination between highly diverged homeologous sequences in Arabidopsis thaliana germinal tissues," Plant Molecular Biology, vol. 63, no. 6, pp. 833-846, 2007.

[42] Q. Chao, C. D. Sullivan, J. M. Getz et al., "Rapid generation of plant traits via regulation of DNA mismatch repair," Plant Biotechnology Journal, vol. 3, no. 4, pp. 399-407, 2005.

[43] A. H. Alou, A. Azaiez, M. Jean, and F. J. Belzile, "Involvement of the Arabidopsis thaliana AtPMS1 gene in somatic repeat instability," Plant Molecular Biology, vol. 56, no. 3, pp. 339349, 2004.

[44] C. Galles, R. L. Gomez, and C. P. Spampinato, "PMS1 from Arabidopsis thaliana: optimization of protein overexpression in Escherichia coli," Molecular Biology Reports, vol. 38, no. 2, pp. 1063-1070, 2011.

[45] R. L. Gomez, C. Galles, and C. P. Spampinato, "High-level production of MSH2 from Arabidopsis thaliana: a DNA mismatch repair system key subunit," Molecular Biotechnology, vol. 47, no. 2, pp. 120-129, 2011.

[46] L. D. Lario, E. Ramirez-Parra, C. Gutierrez, P. Casati, and C. P. Spampinato, "Regulation of plant MSH2 and MSH6 genes in the UV-B-induced DNA damage response," Journal of Experimental Botany, vol. 62, no. 8, pp. 2925-2937, 2011.

[47] K. H. Kraemer, M. M. Lee, and J. Scotto, "Xeroderma pigmentosum. Cutaneous, ocular, and neurologic abnormalities in 830 published cases," Archives of Dermatology, vol. 123, no. 2, pp. 241-250, 1987.

[48] K. H. Kraemer, N. J. Patronas, R. Schiffmann, B. P. Brooks, D. Tamura, and J. J. DiGiovanna, "Xeroderma pigmentosum, trichothiodystrophy and Cockayne syndrome: a complex genotype-phenotype relationship," Neuroscience, vol. 145, no. 4, pp. 1388-1396, 2007.

[49] E. C. Friedberg, G. C. Walker, W. Siede, R. D. Wood, R. A. Schultz, and T. Ellenberger, DNA Repair and Mutagenesis, ASM Press, Washington, DC, USA, 2nd edition, 2005.

[50] A. M. Bhutto and S. H. Kirk, "Population distribution of xeroderma pigmentosum," Advances in Experimental Medicine and Biology, vol. 637, pp. 138-143, 2008.

[51] J. H. J. Hoeijmakers, "Genome maintenance mechanisms for preventing cancer," Nature, vol. 411, no. 6835, pp. 366-374, 2001.

[52] E. C. Friedberg, "How nucleotide excision repair protects against cancer," Nature Reviews Cancer, vol. 1, no. 1, pp. 2233, 2001.

[53] R. Dip, U. Camenisch, and H. Naegeli, "Mechanisms of DNA damage recognition and strand discrimination in human nucleotide excision repair," DNA Repair, vol. 3, no. 11, pp. 1409-1423, 2004.

[54] K. Sugasawa, T. Okamoto, Y. Shimizu, C. Masutani, S. Iwai, and F. Hanaoka, "A multistep damage recognition mechanism for global genomic nucleotide excision repair," Genes and Development, vol. 15, no. 5, pp. 507-521, 2001.

[55] K. Sugasawa, Y. Shimizu, S. Iwai, and F. Hanaoka, "A molecular mechanism for DNA damage recognition by the xeroderma pigmentosum group C protein complex," DNA Repair, vol. 1, no. 1, pp. 95-107, 2002.

[56] J. H. Min and N. P. Pavletich, "Recognition of DNA damage by the Rad4 nucleotide excision repair protein," Nature, vol. 449, no. 7162, pp. 570-575, 2007.

[57] D. Hoogstraten, S. Bergink, V. H. M. Verbiest et al., "Versatile DNA damage detection by the global genome nucleotide excision repair protein XPC," Journal of Cell Science, vol. 121, no. 17, pp. 2850-2859, 2008.

[58] J. P. M. Melis, M. Luijten, L. H. F. Mullenders, and H. van Steeg, "The role of XPC: implications in cancer and oxidative DNA damage," Mutation Research, vol. 728, no. 3, pp. 107117, 2011.

[59] A. F. Fagbemi, B. Orelli, and O. D. Schärer, "Regulation of endonuclease activity in human nucleotide excision repair," DNA Repair, vol. 10, no. 7, pp. 722-729, 2011.

[60] K. Sugasawa, "Xeroderma pigmentosum genes: functions inside and outside DNA repair," Carcinogenesis, vol. 29, no. 3, pp. 455-465, 2008. 
[61] O. D. Schärer, "Achieving broad substrate specificity in damage recognition by binding accessible nondamaged DNA," Molecular Cell, vol. 28, no. 2, pp. 184-186, 2007.

[62] O. Maillard, S. Solyom, and H. Naegeli, "An aromatic sensor with aversion to damaged strands confers versatility to DNA repair," PLoS biology, vol. 5, no. 4, p. e79, 2007.

[63] P. C. Hanawalt and G. Spivak, "Transcription-coupled DNA repair: two decades of progress and surprises," Nature Reviews Molecular Cell Biology, vol. 9, no. 12, pp. 958-970, 2008.

[64] V. Oksenych and F. Coin, "The long unwinding road: XPB and XPD helicases in damaged DNA opening," Cell Cycle, vol. 9, no. 1, pp. 90-96, 2010.

[65] A. Zotter, M. S. Luijsterburg, D. O. Warmerdam et al., "Recruitment of the nucleotide excision repair endonuclease XPG to sites of UV-induced DNA damage depends on functional TFIIH," Molecular and Cellular Biology, vol. 26, no. 23, pp. 8868-8879, 2006.

[66] T. Riedl, F. Hanaoka, and J. M. Egly, "The comings and goings of nucleotide excision repair factors on damaged DNA," EMBO Journal, vol. 22, no. 19, pp. 5293-5303, 2003.

[67] E. Evans, J. Fellows, A. Coffer, and R. D. Wood, "Open complex formation around a lesion during nucleotide excision repair provides a structure for cleavage by human XPG protein," EMBO Journal, vol. 16, no. 3, pp. 625-638, 1997.

[68] E. Evans, J. G. Moggs, J. R. Hwang, J. M. Egly, and R. D. Wood, "Mechanism of open complex and dual incision formation by human nucleotide excision repair factors," EMBO Journal, vol. 16, no. 21, pp. 6559-6573, 1997.

[69] D. Mu, M. Wakasugi, D. S. Hsu, and A. Sancar, "Characterization of reaction intermediates of human excision repair nuclease," Journal of Biological Chemistry, vol. 272, no. 46, pp. 28971-28979, 1997.

[70] R. T. Hess, U. Schwitter, M. Petretta, B. Giese, and H. Naegeli, "Bipartite substrate discrimination by human nucleotide excision repair," Proceedings of the National Academy of Sciences of the United States of America, vol. 94, no. 13, pp. 6664-6669, 1997.

[71] T. Ogi, S. Limsirichaikul, R. M. Overmeer et al., "Three DNA polymerases, recruited by different mechanisms, carry out NER repair synthesis in human cells," Molecular Cell, vol. 37, no. 5, pp. 714-727, 2010.

[72] J. Moser, H. Kool, I. Giakzidis, K. Caldecott, L. H. F. Mullenders, and M. I. Fousteri, "Sealing of chromosomal DNA nicks during nucleotide excision repair requires XRCC1 and DNA ligase III $\alpha$ in a cell-cycle-specific manner," Molecular Cell, vol. 27, no. 2, pp. 311-323, 2007.

[73] R. Schmitz-Hoerner and G. Weissenböck, "Contribution of phenolic compounds to the UV-B screening capacity of developing barley primary leaves in relation to DNA damage and repair under elevated UV-B levels," Phytochemistry, vol. 64, no. 1, pp. 243-255, 2003.

[74] J. Rozema, L. O. Björn, J. F. Bornman et al., "The role of UV-B radiation in aquatic and terrestrial ecosystems-An experimental and functional analysis of the evolution of UV-absorbing compounds," Journal of Photochemistry and Photobiology B, vol. 66, no. 1, pp. 2-12, 2002.

[75] A. E. Stapleton and V. Walbot, "Flavonoids can protect maize DNA from the induction of ultraviolet radiation damage," Plant Physiology, vol. 105, no. 3, pp. 881-889, 1994.

[76] M. Tevini, J. Braun, and G. Fieser, "The protective function of the epidermal layer of rye seedlings against ultraviolet- $B$ radiation," Photochemistry and Photobiology, vol. 53, pp. 329333, 1991.
[77] S. Reuber, J. F. Bornman, and G. Weissenböck, "Phenylpropanoid compounds in primary leaf tissues of rye (Secale cereale). Light response of their metabolism and the possible role in UV-B protection," Physiologia Plantarum, vol. 97, no. 1, pp. 160-168, 1996.

[78] N. Tuteja, M. B. Singh, M. K. Misra, P. L. Bhalla, and R. Tuteja, "Molecular mechanisms of DNA damage and repair: progress in plants," Critical Reviews in Biochemistry and Molecular Biology, vol. 36, no. 4, pp. 337-397, 2001.

[79] A. B. Britt, "DNA damage and repair in plants," Annual Review of Plant Physiology and Plant Molecular Biology, vol. 47, no. 1, pp. 75-100, 1996.

[80] L. G. Landry, A. E. Stapleton, J. Lim et al., "An Arabidopsis photolyase mutant is hypersensitive to ultraviolet-B radiation," Proceedings of the National Academy of Sciences of the United States of America, vol. 94, no. 1, pp. 328-332, 1997.

[81] S. Kimura, Y. Tahira, T. Ishibashi et al., "DNA repair in higher plants; photoreactivation is the major DNA repair pathway in non-proliferating cells while excision repair (nucleotide excision repair and base excision repair) is active in proliferating cells," Nucleic Acids Research, vol. 32, no. 9, pp. 2760-2767, 2004.

[82] M. Ahmad, J. A. Jarillo, L. J. Klimczak et al., "An enzyme similar to animal type II photolyases mediates photoreactivation in arabidopsis," Plant Cell, vol. 9, no. 2, pp. 199-207, 1997.

[83] C. Z. Jiang, J. Yee, D. L. Mitchell, and A. B. Britt, "Photorepair mutants of arabidopsis," Proceedings of the National Academy of Sciences of the United States of America, vol. 94, no. 14, pp. 7441-7445, 1997.

[84] S. Nakajima, M. Sugiyama, S. Iwai et al., "Cloning and characterization of a gene (UVR3) required for photorepair of 6-4 photoproducts in Arabidopsis thaliana," Nucleic Acids Research, vol. 26, no. 2, pp. 638-644, 1998.

[85] B. A. Kunz, H. J. Anderson, M. J. Osmond, and E. J. Vonarx, "Components of nucleotide excision repair and DNA damage tolerance in Arabidopsis thaliana," Environmental and Molecular Mutagenesis, vol. 45, no. 2-3, pp. 115-127, 2005.

[86] D. T. Ribeiro, C. R. MacHado, R. M. A. Costa, U. M. Praekelt, M. A. Van Sluys, and C. F. M. Menck, "Cloning of a cDNA from Arabidopsis thaliana homologous to the human XPB gene," Gene, vol. 208, no. 2, pp. 207-213, 1998.

[87] R. M. A. Costa, P. G. Morgante, C. M. Berra et al., "The participation of AtXPB1, the XPB/RAD25 homologue gene from Arabidopsis thaliana, in DNA repair and plant development," Plant Journal, vol. 28, no. 4, pp. 385-395, 2001.

[88] P. G. Morgante, C. M. Berra, M. Nakabashi, R. M. A. Costa, C. F. M. Menck, and M. A. Van Sluys, "Functional XPB/RAD25 redundancy in Arabidopsis genome: characterization of AtXPB2 and expression analysis," Gene, vol. 344, pp. 93-103, 2005.

[89] N. Tuteja, P. Ahmad, B. B. Panda, and R. Tuteja, "Genotoxic stress in plants: shedding light on DNA damage, repair and DNA repair helicases," Mutation Research, vol. 681, no. 2-3, pp. 134-149, 2009.

[90] Z. Liu, S. W. Hong, M. Escobar et al., "Arabidopsis UVH6, a homolog of human XPD and yeast RAD3 DNA repair genes, functions in DNA repair and is essential for plant growth," Plant Physiology, vol. 132, no. 3, pp. 1405-1414, 2003.

[91] T. Ishibashi, S. Kimura, T. Yamamoto et al., "Rice UVdamaged DNA binding protein homologues are most abundant in proliferating tissues," Gene, vol. 308, no. 1-2, pp. 79$87,2003$. 
[92] S. Biedermann and H. Hellmann, "The DDBla interacting proteins ATCSA-1 and DDB2 are critical factors for UVB tolerance and genomic integrity in Arabidopsis thaliana," Plant Journal, vol. 62, no. 3, pp. 404-415, 2010.

[93] A. Koga, T. Ishibashi, S. Kimura, Y. Uchiyama, and K. Sakaguchi, "Characterization of T-DNA insertion mutants and RNAi silenced plants of Arabidopsis thaliana UV-damaged DNA binding protein 2 (AtUV-DDB2)," Plant Molecular Biology, vol. 61, no. 1-2, pp. 227-240, 2006.

[94] J. Molinier, E. Lechner, E. Dumbliauskas, and P. Genschik, "Regulation and role of arabidopsis CUL4-DDB1A-DDB2 in maintaining genome integrity upon UV stress," PLoS Genetics, vol. 4, no. 6, Article ID e1000093, 2008.

[95] F. Gallego, O. Fleck, A. Li, J. Wyrzykowska, and B. Tinland, "AtRAD1, a plant homologue of human and yeast nucleotide excision repair endonucleases, is involved in dark repair of UV damages and recombination," Plant Journal, vol. 21, no. 6, pp. 507-518, 2000.

[96] Z. Liu, G. S. Hossain, M. A. Islas-Osuna, D. L. Mitchell, and D. W. Mount, "Repair of UV damage in plants by nucleotide excision repair: arabidopsis UVH1 DNA repair gene is a homolog of Saccharomyces cerevisiae Rad1," Plant Journal, vol. 21, no. 6, pp. 519-528, 2000.

[97] S. B. Preuss and A. B. Britt, "A DNA-damage-induced cell cycle checkpoint in arabidopsis," Genetics, vol. 164, no. 1, pp. 323-334, 2003.

[98] A. L. Fidantsef, D. L. Mitchell, and A. B. Britt, "The Arabidopsis UVH1 gene is a homolog of the yeast repair endonuclease RAD1," Plant Physiology, vol. 124, no. 2, pp. 579-586, 2000.

[99] Z. Liu, J. D. Hall, and D. W. Mount, "Arabidopsis UVH3 gene is a homolog of the Saccharomyces cerevisiae RAD2 and human XPG DNA repair genes," Plant Journal, vol. 26, no. 3, pp. 329-338, 2001.

[100] L. H. Thompson and D. Schild, "Recombinational DNA repair and human disease," Mutation Research, vol. 509, no. 1-2, pp. 49-78, 2002.

[101] H. H. Chun and R. A. Gatti, "Ataxia-telangiectasia, an evolving phenotype," DNA Repair, vol. 3, no. 8-9, pp. 1187-1196, 2004.

[102] A. Nowak-Wegrzyn, T. O. Crawford, J. A. Winkelstein, K. A. Carson, and H. M. Lederman, "Immunodeficiency and infections in ataxia-telangiectasia," Journal of Pediatrics, vol. 144, no. 4, pp. 505-511, 2004.

[103] P. J. McKinnon, "ATM and ataxia telangiectasia. Second in molecular medicine review series," EMBO Reports, vol. 5, no. 8, pp. 772-776, 2004.

[104] R. A. Gatti, S. Becker-Catania, H. H. Chun et al., "The pathogenesis of ataxia-telangiectasia: learning from a Rosetta Stone," Clinical Reviews in Allergy and Immunology, vol. 20, no. 1, pp. 87-108, 2001.

[105] Y. Shiloh, "ATM and related protein kinases: safeguarding genome integrity," Nature Reviews Cancer, vol. 3, no. 3, pp. 155-168, 2003.

[106] C. J. Bakkenist and M. B. Kastan, "DNA damage activates ATM through intermolecular autophosphorylation and dimer dissociation," Nature, vol. 421, no. 6922, pp. 499-506, 2003.

[107] R. Kitagawa, C. J. Bakkenist, P. J. McKinnon, and M. B. Kastan, "Phosphorylation of SMC1 is a critical downstream event in the ATM-NBS1-BRCA1 pathway," Genes and Development, vol. 18, no. 12, pp. 1423-1438, 2004.
[108] A. Bensimon, R. Aebersold, and Y. Shiloh, "Beyond ATM: the protein kinase landscape of the DNA damage response," FEBS Letters, vol. 585, no. 11, pp. 1625-1639, 2011.

[109] Y. Lee, M. J. Chong, and P. J. McKinnon, "Ataxia telangiectasia mutated-dependent apoptosis after genotoxic stress in the developing nervous system is determined by cellular differentiation status," Journal of Neuroscience, vol. 21, no. 17, pp. 6687-6693, 2001.

[110] A. Alexander and C. L. Walker, "Differential localization of ATM is correlated with activation of distinct downstream signaling pathways," Cell Cycle, vol. 9, no. 18, pp. 3685-3686, 2010.

[111] C. Cosentino, D. Grieco, and V. Costanzo, "ATM activates the pentose phosphate pathway promoting anti-oxidant defence and DNA repair," EMBO Journal, vol. 30, no. 3, pp. 546-555, 2011.

[112] Z. Guo, R. Deshpande, and T. T. Paull, "ATM activation in the presence of oxidative stress," Cell Cycle, vol. 9, no. 24, pp. 4805-4811, 2010.

[113] Z. Guo, S. Kozlov, M. F. Lavin, M. D. Person, and T. T. Paull, "ATM activation by oxidative stress," Science, vol. 330, no. 6003, pp. 517-521, 2010.

[114] V. Garcia, M. Salanoubat, N. Choisne, and A. Tissier, "An ATM homologue from Arabidopsis thaliana: complete genomic organisation and expression analysis," Nucleic Acids Research, vol. 28, no. 8, pp. 1692-1699, 2000.

[115] V. Garcia, H. Bruchet, D. Camescasse, F. Granier, D. Bouchez, and A. Tissier, "AtATM is essential for meiosis and the somatic response to DNA damage in plants," Plant Cell, vol. 15, no. 1, pp. 119-132, 2003.

[116] N. Fulcher and R. Sablowski, "Hypersensitivity to DNA damage in plant stem cell niches," Proceedings of the National Academy of Sciences of the United States of America, vol. 106, no. 49, pp. 20984-20988, 2009.

[117] K. M. Culligan, C. E. Robertson, J. Foreman, P. Doerner, and A. B. Britt, "ATR and ATM play both distinct and additive roles in response to ionizing radiation," Plant Journal, vol. 48, no. 6, pp. 947-961, 2006.

[118] L. Ricaud, C. Proux, J. P. Renou et al., "ATM-mediated transcriptional and developmental responses to $\gamma$-rays in Arabidopsis," PLoS ONE, vol. 2, no. 5, article e430, 2007.

[119] S. Adachi, K. Minamisawaa, V. Okushima et al., "Programmed induction of endoreduplication by DNA doublestrand breaks in Arabidopsis," Proceedings of the National Academy of Sciences of the United States of America, vol. 108, pp. 10004-10009, 2011.

[120] K. Yoshiyama, P. A. Conklin, N. D. Huefner, and A. B. Britt, "Suppressor of gamma response 1 (SOG1) encodes a putative transcription factor governing multiple responses to DNA damage," Proceedings of the National Academy of Sciences of the United States of America, vol. 106, no. 31, pp. 1284312848, 2009.

[121] T. Furukawa, M. J. Curtis, C. M. Tominey et al., "A shared DNA-damage-response pathway for induction of stem-cell death by UVB and by gamma irradiation," DNA Repair, vol. 9, no. 9, pp. 940-948, 2010.

[122] V. Campuzano, L. Montermini, M. D. Moltò et al., "Friedreich's ataxia: autosomal recessive disease caused by an intronic GAA triplet repeat expansion," Science, vol. 271, no. 5254, pp. 1423-1427, 1996.

[123] M. Pandolfo, "The molecular basis of Friedreich ataxia," Advances in Experimental Medicine and Biology, vol. 516, pp. 99-118, 2002. 
[124] H. Puccio and M. Konig, "Friedreich ataxia: a paradigm for mitochondrial diseases," Current Opinion in Genetics and Development, vol. 12, no. 3, pp. 272-277, 2002.

[125] M. Pandolfo and A. Pastore, "The pathogenesis of Friedreich ataxia and the structure and function of frataxin," Journal of Neurology, vol. 256, no. 1, pp. 9-17, 2009.

[126] H. Puccio, "Multicellular models of Friedreich ataxia," Journal of Neurology, vol. 256, no. 1, pp. 18-24, 2009.

[127] R. Santos, S. Lefevre, D. Sliwa, A. Seguin, J. M. Camadro, and E. Lesuisse, "Friedreich ataxia: molecular mechanisms, redox considerations, and therapeutic opportunities," Antioxidants and Redox Signaling, vol. 13, no. 5, pp. 651-690, 2010.

[128] U. J. Dijkstra, J. L. Willems, E. M. Joosten, and F. J. Gabreëls, "Friedreich ataxia and low pyruvate carboxylase activity in liver and fibroblasts," Annals of Neurology, vol. 13, no. 3, pp. 325-327, 1983.

[129] M. Babcock, D. De Silva, R. Oaks et al., "Regulation of mitochondrial iron accumulation by Yfhlp, a putative homolog of frataxin," Science, vol. 276, no. 5319, pp. 1709$1712,1997$.

[130] V. Campuzano, L. Montermini, Y. Lutz et al., "Frataxin is reduced in Friedreich ataxia patients and is associated with mitochondrial membranes," Human Molecular Genetics, vol. 6, no. 11, pp. 1771-1780, 1997.

[131] T. J. Gibson, E. V. Koonin, G. Musco, A. Pastore, and P. Bork, "Friedreich's ataxia protein: phylogenetic evidence for mitochondrial dysfunction," Trends in Neurosciences, vol. 19, no. 11, pp. 465-468, 1996.

[132] H. Koutnikova, V. Campuzano, F. Foury, P. Dollé, O. Cazzalini, and M. Koenig, "Studies of human, mouse and yeast homologues indicate a mitochondrial function for frataxin," Nature Genetics, vol. 16, no. 4, pp. 345-351, 1997.

[133] M. V. Busi, E. J. Zabaleta, A. Araya, and D. F. Gomez-Casati, "Functional and molecular characterization of the frataxin homolog from Arabidopsis thaliana," FEBS Letters, vol. 576, no. 1-2, pp. 141-144, 2004.

[134] M. Ristow, M. F. Pfister, A. J. Yee et al., "Frataxin activates mitochondrial energy conversion and oxidative phosphorylation," Proceedings of the National Academy of Sciences of the United States of America, vol. 97, pp. 12239-12243, 2000.

[135] O. S. Chen, S. Hemenway, and J. Kaplan, "Inhibition of Fe-S cluster biosynthesis decreases mitochondrial iron export: evidence that Yfh1p affects Fe-S cluster synthesis," Proceedings of the National Academy of Sciences of the United States of America, vol. 99, no. 19, pp. 12321-12326, 2002.

[136] U. Mühlenhoff, N. Richhardt, M. Ristow, G. Kispal, and R. Lill, "The yeast frataxin homolog Yfhlp plays a specific role in the maturation of cellular Fe/S proteins," Human Molecular Genetics, vol. 11, no. 17, pp. 2025-2036, 2002.

[137] M. A. Huynen, B. Snel, P. Bork, and T. J. Gibson, "The phylogenetic distribution of frataxin indicates a role in iron-sulfur cluster protein assembly," Human Molecular Genetics, vol. 10, no. 21, pp. 2463-2468, 2001.

[138] M. V. Busi and D. F. Gomez-Casati, "Exploring frataxin function," IUBMB Life, vol. 64, pp. 56-63, 2012.

[139] M. V. Maliandi, M. V. Busi, M. Clemente, E. J. Zabaleta, A. Araya, and D. F. Gomez-Casati, "Expression and one-step purification of recombinant Arabidopsis thaliana frataxin homolog (AtFH)," Protein Expression and Purification, vol. 51, no. 2, pp. 157-161, 2007.

[140] M. V. Busi, M. V. Maliandi, H. Valdez et al., "Deficiency of Arabidopsis thaliana frataxin alters activity of mitochondrial Fe-S proteins and induces oxidative stress," Plant Journal, vol. 48, no. 6, pp. 873-882, 2006.
[141] E. Lesuisse, R. Santos, B. F. Matzanke, S. A. B. Knight, J. M. Camadro, and A. Dancis, "Iron use for haeme synthesis is under control of the yeast frataxin homologue (Yfh1)," Human Molecular Genetics, vol. 12, no. 8, pp. 879-889, 2003.

[142] M. V. Maliandi, M. V. Busi, V. R. Turowski, L. Leaden, A. Araya, and D. F. Gomez-Casati, "The mitochondrial protein frataxin is essential for heme biosynthesis in plants," FEBS Journal, vol. 278, no. 3, pp. 470-481, 2011.

[143] R. A. Schoenfeld, E. Napoli, A. Wong et al., "Frataxin deficiency alters heme pathway transcripts and decreases mitochondrial heme metabolites in mammalian cells," Human Molecular Genetics, vol. 14, no. 24, pp. 3787-3799, 2005.

[144] N. Ventura, S. Rea, S. T. Henderson, I. Condo, T. E. Johnson, and R. Testi, "Reduced expression of frataxin extends the lifespan of Caenorhabditis elegans," Aging Cell, vol. 4, no. 2, pp. 109-112, 2005.

[145] P. R. Anderson, K. Kirby, A. J. Hilliker, and J. P. Phillips, "RNAi-mediated suppression of the mitochondrial iron chaperone, frataxin, in Drosophila," Human Molecular Genetics, vol. 14, no. 22, pp. 3397-3405, 2005.

[146] R. Santos, N. Buisson, S. A. B. Knight, A. Dancis, J. M. Camadro, and E. Lesuisse, "Candida albicans lacking the frataxin homologue: a relevant yeast model for studying the role of frataxin," Molecular Microbiology, vol. 54, no. 2, pp. 507-519, 2004.

[147] G. Tan, E. Napoli, F. Taroni, and G. Cortopassi, "Decreased expression of genes involved in sulfur amino acid metabolism in frataxin-deficient cells," Human Molecular Genetics, vol. 12, no. 14, pp. 1699-1711, 2003.

[148] E. Vivas, E. Skovran, and D. M. Downs, "Salmonella enterica strains lacking the frataxin homolog cyaY show defects in Fe-S cluster metabolism in vivo," Journal of Bacteriology, vol. 188, no. 3, pp. 1175-1179, 2006.

[149] R. Lill and U. Mühlenhoff, "Maturation of iron-sulfur proteins in eukaryotes: mechanisms, connected processes, and diseases," Annual Review of Biochemistry, vol. 77, pp. 669-700, 2008.

[150] J. Balk and S. Lobréaux, "Biogenesis of iron-sulfur proteins in plants," Trends in Plant Science, vol. 10, no. 7, pp. 324-331, 2005.

[151] E. Napoli, D. Morin, R. Bernhardt, A. Buckpitt, and G. Cortopassi, "Hemin rescues adrenodoxin, heme a and cytochrome oxidase activity in frataxin-deficient oligodendroglioma cells," Biochimica et Biophysica Acta, vol. 1772, no. 7, pp. 773-780, 2007.

[152] Y. Hatefi, "The mitochondrial electron transport and oxidative phosphorylation system," Annual Review of Biochemistry, vol. 54, pp. 1015-1069, 1985.

[153] M. Saraste, "Oxidative phosphorylation at the fin de siecle," Science, vol. 283, no. 5407, pp. 1488-1493, 1999.

[154] S. DiMauro and E. A. Schon, "Mitochondrial respiratorychain diseases," New England Journal of Medicine, vol. 348, no. 26, pp. 2656-2668, 2003.

[155] F. Foury and M. Kucej, "Yeast mitochondrial biogenesis: a model system for humans?" Current Opinion in Chemical Biology, vol. 6, no. 1, pp. 106-111, 2002.

[156] C. Schwimmer, M. Rak, L. Lefebvre-Legendre, S. DuvezinCaubet, G. Plane, and J. P. di Rago, "Yeast models of human mitochondrial diseases: from molecular mechanisms to drug screening," Biotechnology Journal, vol. 1, no. 3, pp. 270-281, 2006.

[157] M. J. Falk, Z. Zhang, J. R. Rosenjack et al., "Metabolic pathway profiling of mitochondrial respiratory chain mutants in 
C. elegans," Molecular Genetics and Metabolism, vol. 93, no. 4, pp. 388-397, 2008.

[158] V. Petruzzella and S. Papa, "Mutations in human nuclear genes encoding for subunits of mitochondrial respiratory complex I: the NDUFS4 gene," Gene, vol. 286, no. 1, pp. 149$154,2002$.

[159] J. L. Loeffen, J. A. Smeitink, J. M. Trijbels et al., "Isolated complex I deficiency in children: clinical, biochemical and genetic aspects," Human Mutation, vol. 15, pp. 123-134, 2000.

[160] S. Papa, V. Petruzzella, S. Scacco et al., "Pathogenetic mechanisms in hereditary dysfunctions of complex I of the respiratory chain in neurological diseases," Biochimica et Biophysica Acta, vol. 1787, no. 5, pp. 502-517, 2009.

[161] C. A. Ingraham, L. S. Burwell, J. Skalska et al., "NDUFS4: creation of a mouse model mimicking a Complex I disorder," Mitochondrion, vol. 9, no. 3, pp. 204-210, 2009.

[162] L. Van Den Heuvel, W. Ruitenbeek, R. Smeets et al., "Demonstration of a new pathogenic mutation in human complex I deficiency: a 5-bp duplication in the nuclear gene encoding the 18-kD (AQDQ) subunit," American Journal of Human Genetics, vol. 62, no. 2, pp. 262-268, 1998.

[163] S. Papa, S. Scacco, A. M. Sardanelli et al., "Mutation in the NDUFS4 gene of complex I abolishes cAMP-dependent activation of the complex in a child with fatal neurological syndrome," FEBS Letters, vol. 489, no. 2-3, pp. 259-262, 2001.

[164] V. Petruzzella, R. Vergari, I. Puzziferri et al., "A nonsense mutation in the NDUFS4 gene encoding the $18 \mathrm{kDA}$ (AQDQ) subunit of complex I abolishes assembly and activity of the complex in a patient with Leigh-like syndrome," Human Molecular Genetics, vol. 10, no. 5, pp. 529-535, 2001.

[165] S. Scacco, V. Petruzzella, S. Budde et al., "Pathological mutations of the human NDUFS4 gene of the $18-\mathrm{kDa}$ (AQDQ) subunit of complex I affect the expression of the protein and the assembly and function of the complex," Journal of Biological Chemistry, vol. 278, no. 45, pp. 4416144167, 2003.

[166] E. Leshinsky-Silver, A. S. Lebre, L. Minai et al., "NDUFS4 mutations cause Leigh syndrome with predominant brainstem involvement," Molecular Genetics and Metabolism, vol. 97, no. 3, pp. 185-189, 2009.

[167] E. H. Meyer, T. Tomaz, A. J. Carroll et al., "Remodeled respiration in ndufs4 with low phosphorylation efficiency suppresses Arabidopsis germination and growth and alters control of metabolism at night," Plant Physiology, vol. 151, pp. 603-619, 2009. 

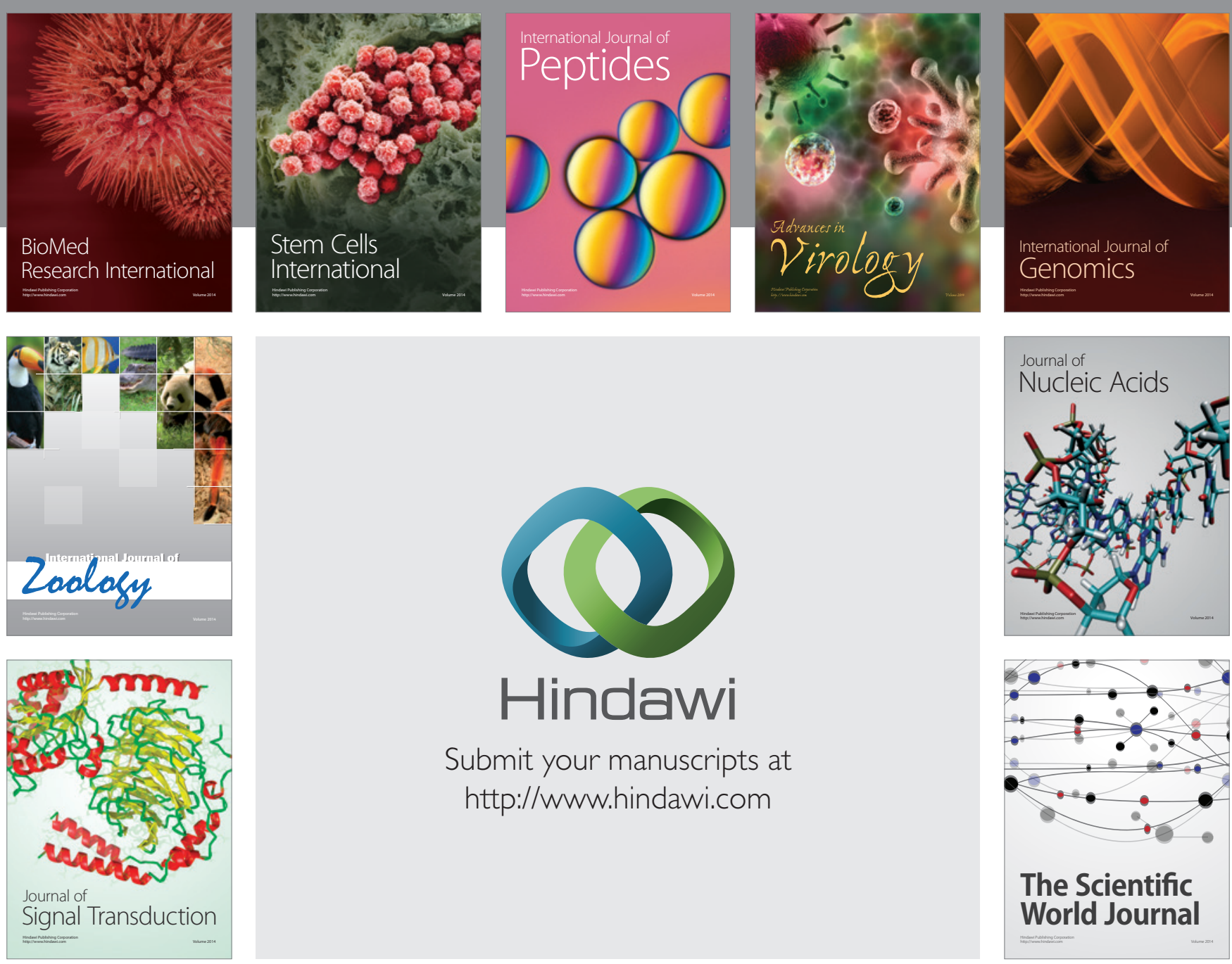

Submit your manuscripts at

http://www.hindawi.com
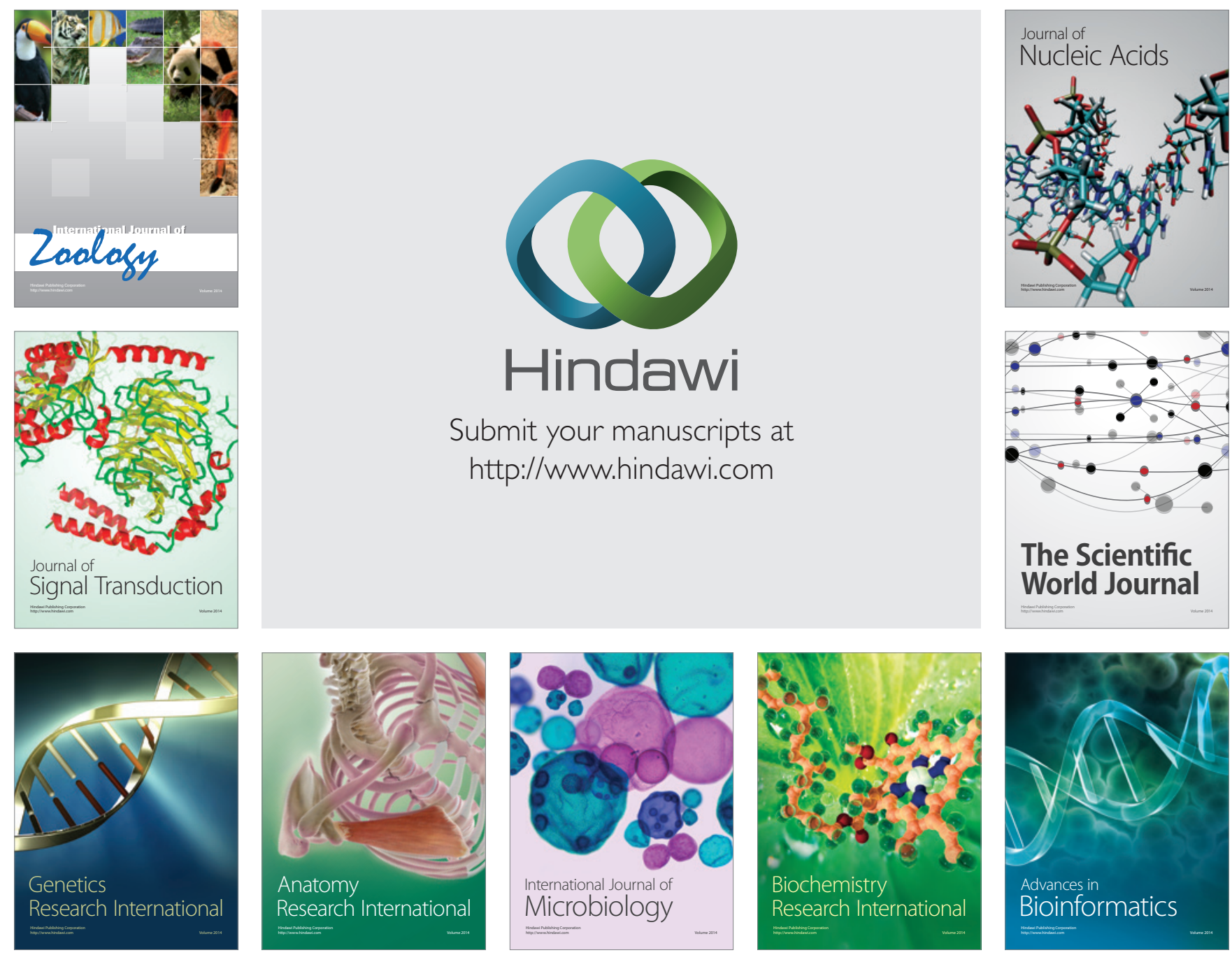

The Scientific World Journal
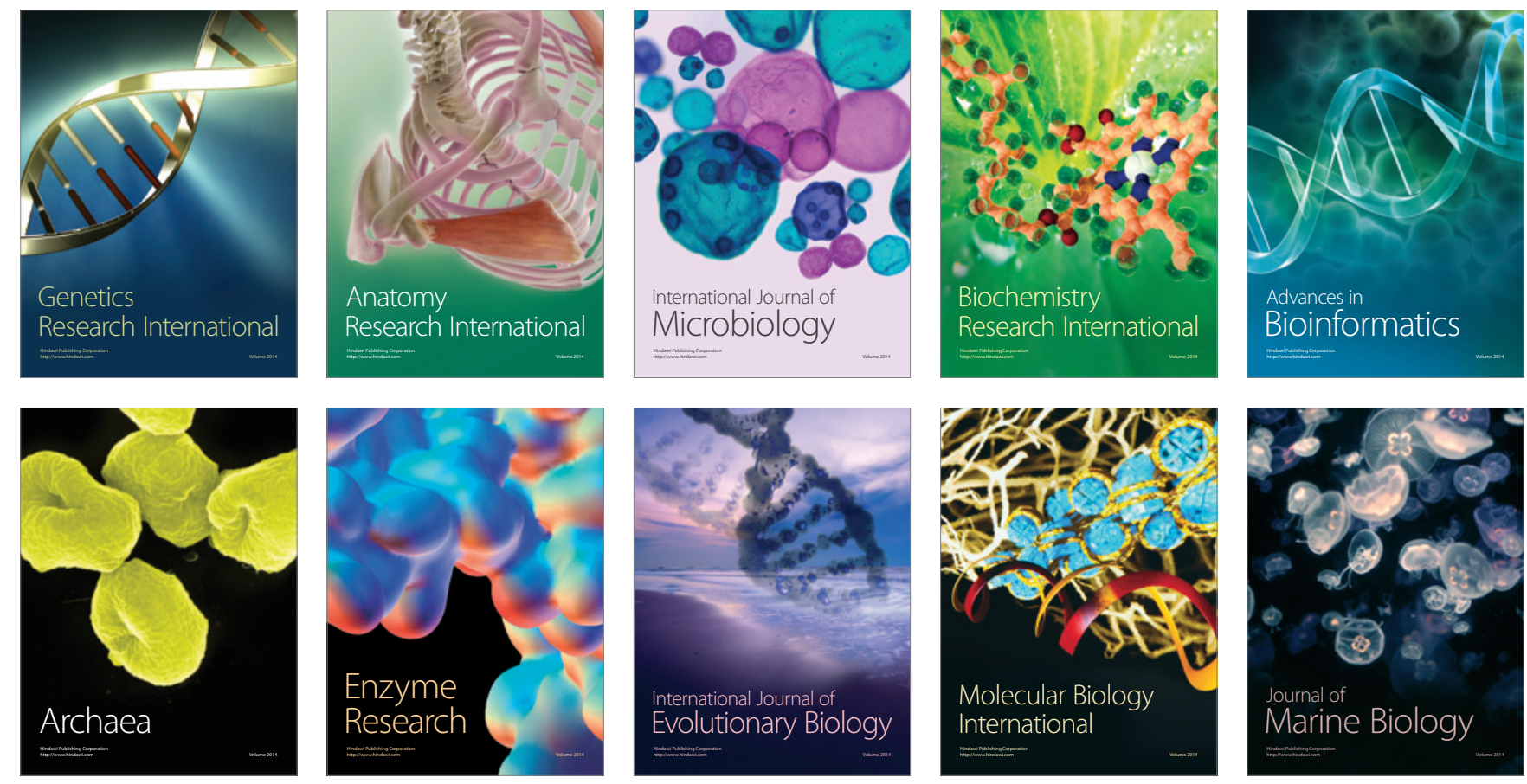